Due to an unfortunate oversight the following abstract was not published in the book of abstracts, Supplement 2 to Volume 242 , No. 6, 1995

643

TREATMENT OF REMITTING-RELAPSING MULTIPLE SCLEROSIS (MS) WITH CLADRIBINE: RESULTS OF AN OPEN PILOT STUDY AT 18 MONTHS. Z. Stelmasiak, J. Nowicki, J. Solski, B. Jakubowska, M. Ryba, P. Grieb, Lublin and Warsaw, Poland.

Cladribine (2-chloro-2'-deoxyadenosine, 2CdA), a selectively hymphocytotoxic compound, was reported to halt disease progression in chronic progressive MS when dose $0.087-0.1 \mathrm{mg} / \mathrm{Kg} /$ day was given in week-long iv infusions repeated monthly. 4-6 times [Sipe et al., Lancet 1994, 344:9], but considerable and possibly dangerous hematologic toxicity was observed [Beutler et al., Acta
Haematol 1994, 91:10] In the present study eleven patients with remitting-relapsing MS were treated with cladribine (synthesized by Z. Kazimierczuk, Dept. Biophysics, University of Warsaw, purity $>99 \%$ by HPLC). The drug was given once daily, sc $(5 \mathrm{mg})$ or orally $(10 \mathrm{mg})$ on five consecutive days. The treatments were repeated monthly during the first six months, and further were given at 9 and/or 12 months. Blood morphology and neurological status were monitored before each treatment and 3 months after the last one. A gradual decline in lymphocyte counts was noted, to $40 \%$ of the control value five months after the therapy was initiated. Except of a slight, clinically insignificant drop in platelet counts, no toxicity (hematologic or systemic) was observed. Disease activity seemed reduced. The total number of relapses reported by all patients in the group was 19 per year over two-year period before the treatment, while during 18 months following the start of cladribine administration only 7 relapses were reported. The EDSS score improved in most patients. Cladribine dosing employed in the present study appear to be well tolerated, and the drug deserves further evaluation in remitting-relapsing MS.

ANNOUNCEMENTS

\section{First Conference} on Biological and Clinical Aspects of Thymic Epithelial Tumors and Slide Workshop on the Histopathology of Thymic Tumors 14-18 April 1996, Würzburg, Germany

For further information, please contact. Prof. Dr. K. Müller-Hermelink, Department of Pathology, Universität Würzburg, Josef-Schneider-Strasse 2, D-97080 Würzburg, Germany; Tel.: 49-931-2013858, FAX: 49-931-201-3505

\section{VIlth Northern Lights Neuroscience Symposium Multiple Sclerosis - Recent Concepts, Advances in Diagnosis, Disease Monitoring, and Therapy 12-14 May 1996. Bergen, Norway \\ For further information, please contact: Dr. Sverre J. Mørk, Department of Pathol ogy, The Gade Institute, Haukeland Hos- pital, 5021 Bergen, Norway; Tel.: 0047- 55-972590, FAX: 0047-55-972577}

\author{
Sixth Meeting \\ of the European Neurological Society \\ 8-12 June 1996. The Hague, \\ The Netherlands \\ For further information, please contact: \\ Administrative Secretariat ENS 1996, \\ c/o AKM Congress Service, P.O. Box, \\ CH-4005 Basel, Switzerland; Tel.: 0041 - \\ 61-691-5111, FAX: 0041-61-691-8189
}

\section{1st Meeting of the Canadian Congress of Neurological Sciences} 25-29 June 1996, London Ontario, Canada

For further information, please contact: Susan M. Markey, Canadian Congress of Neurological Sciences, Suite 810, 906 12th Avenue SW, Calgary AB T2R 1K7, Canada; Tel.: (403) 229-9544, FAX: (403) 229-1661

10th World Congress of the International Association for the Scientific Study of Intellectuell Disability (IASSID) 8-13 July 1996. Helsinki, Finland
For further information, please contact: Prof. Trevor R. Parmenter, Unit for Community Integration Studies, School of Education, Macquarie University, Sydney NSW 2109, Australia; Tel.: +61-2-8508706, FAX +61-2-850-9397, E-mail: tparm@ted.educ.mq.edu.au

\section{0th International Symposium on Cerebral Hemodynamics in Association with the 1st Meeting of The European Society of Neurosonology and Cerebral Hemodynamics 29 August-1 September 1996, Munich, Germany}

For further information, please contact: Prof. Dr. J. Klingelhöfer, Neurologische Klinik der Technischen Universität, Möhlstrasse 28, D-81675 München, Germany; Tel.: +49-89-4140-4699, FAX: $+49-89-4140-4867$

Joint 3rd World Stroke Congress and 5th European Stroke Conference 1-5 September 1996, Munich, Germany 